\title{
Effects of nanocellulose on Alginate/Gelatin Bio-inks for Extrusion-based 3D Printing
}

\author{
Chenyang Han, ${ }^{\text {a }}$ Xinyi Wang, ${ }^{a}$ Zhongjin Ni, ${ }^{a} *$ Yihua Ni, ${ }^{a}$ Weiwei Huan, ${ }^{\mathrm{b}}$ Yan Lv, ${ }^{\mathrm{a}}$ and \\ Shuyang Bai ${ }^{\text {a }}$
}

\begin{abstract}
Cellulose nanofibers (NFC) have attracted special attention in the field of extrusion-based three-dimensional (3D) bioprinting due to their good biocompatibility, excellent mechanical properties, and outstanding shearthinning property. In this study, by mixing cellulose nanofibers suspension with sodium alginate (SA) and gelatin (GEL) solution, five groups of composite bio-inks with different NFC concentrations were prepared. The effects of NFC on the performance of the SA/GEL matrix hydrogels were analyzed by morphological observation, rheological property testing, mechanical property testing, swelling property testing, and printability analysis. The rheological results showed that the addition of NFC noticeably increased the viscosity of biological inks with low shear rates; therefore, the printed scaffolds maintained their structure better during the $3 \mathrm{D}$ printing process. After crosslinking with calcium chloride $\left(\mathrm{CaCl}_{2}\right)$, the fidelity of the NFC/SA/GEL composite hydrogel structure was better than that of the SA/GEL hydrogel. Moreover, the structural properties were strengthened, and the mechanical stabilities of the composite hydrogels improved when NFC was added. Therefore, this study provided an easy way to improve the printability of extrusion-based 3D printing and the potential use of nanocellulose.
\end{abstract}

Keywords: Nanocellulose; Alginate; Gelatin; Extrusion-based 3D printing; Printability

Contact information: a: College of Engineering, Zhejiang A\&F University, No. 666 Wusu Street, Hang Zhou, China; b: College of Science, Zhejiang A\&F University, No. 666 Wusu Street, Hang Zhou, China; *Corresponding author: zafu_neezj@163.com

\section{INTRODUCTION}

Three-dimensional bioprinting is an emerging technology employed to fabricate scaffolds for tissue engineering applications (Derby 2012; Markstedt et al. 2015; Tabriz et al. 2015; Dai et al. 2019). It is an additive manufacturing technique that allows fabrication of scaffolds with high structural complexity and design flexibility that overcome the limitations of traditional tissue engineering (Jiang et al. 2018). In general, 3D printing technologies are classified under four main groups, which include extrusion-based methods, particle fusion-based methods, light induced (photopolymerization) methods, and inkjet printing (Mandrycky et al. 2016; Müller et al. 2017; Chinga-Carrasco 2018; Dai et al. 2019). The bioprinting technique determines which biomaterial inks can be used. Biomaterial ink development is one of the most challenging aspects of the bioprinting process. An ideal ink meets both the biological requirements and the requirements necessary for good printability (Chung et al. 2013). These biomaterials should be printable, biocompatible, biodegradable, form safe degradation byproducts, and have appropriate mechanical properties and low cytotoxicity, etc. (Abouzeid et al. 2018). As multi- 
component biomaterial inks can overcome the limitations of single-component biomaterial inks, this research focused on this issue.

Hydrogels have been identified as attractive materials in tissue engineering for biomaterial inks due to their structural similarity to the extracellular matrix (ECM), which allows for better cell attachment, growth, and function (Kirchmajer et al. 2015; Naseri et al. 2016). Furthermore, a hydrogel must be viscous enough to keep its shape during printing and must have crosslinking abilities to retain the 3D structure after printing. Crosslinking can occur by ionic crosslinking, temperature change, and UV photopolymerization (Xu et al. 2019). Sodium alginate (SA) is a natural biopolymer that consists of two monosaccharide units, i.e., $\beta$-D-mannuronate and $\alpha$-L-guluronate guluronic acids (Chung et al. 2013; Naseri et al. 2016; Aarstad et al. 2017; Nguyen et al. 2017). Due to its ionic crosslinking ability under mild conditions and its ability to enhance the viscosity of solutions, SA or SA mixtures have been widely utilized to form hydrogels (Chung et al. 2013; Florczyk et al. 2013; Nguyen et al. 2019). Divalent cations replace sodium ions in alginate and binding long chain alginate molecules, which results in the formation of a 3D gel assembly called an "egg box". In general, $\mathrm{Ca}^{2+}$ provided by $\mathrm{CaCl}_{2}$ is the most commonly used divalent cation (Lee and Mooney 2012; Liu et al. 2015a). However, alginate is not suitable for cell attachment and function due to its lack of cell adhesive moieties; therefore, it is often blended with other biopolymers such as a gelatin (Zhao et al. 2014; Wang et al. 2016; Sultan and Mathew 2018). Gelatin, a derivative of collagen, resembles the biological structure of collagen in native ECM tissues. Gelatin retains its natural cell binding motifs, such as RGD peptides, which improve cell responses, such as cell adhesion, proliferation, migration, and differentiation (Liu and Chan-Park 2010; Yue et al. 2015; Xu et al. 2019), but it is difficult to directly print gelatin scaffolds with extrusion-based 3D printing due to its low viscosity. Therefore, by blending gelatin with sodium alginate to form biomaterial inks, the temperature crosslinking characteristics of gelatin and the ionic crosslinking characteristics of sodium alginate can be well used in extrusion-based 3D printing (He et al. 2016). The cited authors found that a bio-ink consisting of $2.5 \% \mathrm{w} / \mathrm{v}$ alginate and $8 \% \mathrm{w} / \mathrm{v}$ gelatin has better printability than other concentrations. However, it is limited by the highly demanding printing environment.

Nanoengineered hydrogels have been investigated for a range of biomedical and biotechnological applications (Gaharwar et al. 2014; Carrow and Gaharwar 2015; Wang et al. 2016). Small amounts of nanoparticles added to hydrogels can result in remarkable alterations in various physical and chemical characteristics, which include increased stiffness and shear-thinning (Gao et al. 2014; Chimene et al. 2016; Jaiswal et al. 2016; Naseri et al. 2016; Thakur et al. 2016; Luo et al. 2018; Gao et al. 2019). Cellulose is one of the most abundant renewable resources in nature. Because of its biocompatibility, biodegradability, and low toxicity, cellulose has received increased interest as a biomaterial (Naseri et al. 2016). Nanocellulose is the basic unit of cellulose, and it maintains the crystal structure and hydrogen bond interaction of natural cellulose type I and has high surface area, high strength, and tunable surface chemistry (Ahrem et al. 2014; Dai et al. 2019; Du et al. 2019). Due to their high mechanical strength, nanocellulose, including nanofibrillated cellulose (NFC), cellulose nanocrystals (CNC), and bacterial nanocellulose (BNC), have been widely studied to enhance the mechanical properties and structural stability of hydrogels (Dash et al. 2013; Ooi et al. 2016; Wang et al. 2016; Nguyen et al. 2017; Shin et al. 2017; Gao et al. 2019). Mechanical strength of scaffolds plays a significant role in their applications to meet the bioenvironmental needs. NFC reinforcement provides the potential applications in bearing structures such as cartilage and bone. In particular, the 
high zero shear viscosity and strong shear thinning make nanocellulose biomaterial inks appropriate for extrusion-based 3D printing without additional sol-gel transition conditions (Müller et al. 2017; Siqueira et al. 2017; Dai et al. 2019; Gao et al. 2019).

In this study, a 3D-printable cellulose nanofibers (NFC)-based biocompatible nanocomposite ink with alginate and gelatin as the matrix phase is presented. Incorporating nanocellulose with alginate and gelatin acted as both a viscosity modifier and a mechanical property enhancer. The influence of NFC on the performance of SA/GEL matrix hydrogels was analyzed by morphology observation, rheological property testing, mechanical property testing, and swelling property testing. Finally, the NFC/SA/GEL composite inks were used for extrusion-based 3D printing to analyze their printability and the shape fidelity of models after crosslinking via $\mathrm{CaCl}_{2}$ solution.

\section{EXPERIMENTAL}

\section{Materials}

The sodium alginate (SA) and the gelatin (GEL) were both purchased from Sinopharm Chemical Reagent Co., Ltd. (Shanghai, China). The YH101 nanocellulose (NFC) with an average length of $20 \mathrm{um}$ to $80 \mathrm{um}$ and an average diameter of $50 \mathrm{~nm}$ to 200 nm was supplied by Intelligent Chemicals Pty Ltd. (Wuxi, China).

\section{Methods}

Ink preparation

Sodium alginate and gelatin were used as the matrix to prepare the biomaterial ink. The SA/GEL solution was prepared by dissolving SA and GEL into deionized water and placed in a magnetic stirrer for $12 \mathrm{~h}$ at $37{ }^{\circ} \mathrm{C}$ to make the final SA/GEL solution with a concentration of $2.5 \% \mathrm{w} / \mathrm{v}$ SA and $8 \% \mathrm{w} / \mathrm{v}$ GEL. In this study, YH101 nanocellulose was distributed in deionized water followed by using ultra sonication for $30 \mathrm{~min}$. Then stirring was performed for $2 \mathrm{~h}$ to disperse the nanocellulose suspension evenly. The NFC/SA/GEL inks were prepared by adding the NFC suspension into the SA/GEL solution with continuous stirring at $37{ }^{\circ} \mathrm{C}$ for $12 \mathrm{~h}$, which resulted in NFC/SA/GEL inks with five combinations: $0 \% / 2.5 \% / 8 \%, 0.25 \% / 2.5 \% / 8 \%, 0.5 \% / 2.5 \% / 8 \%, 0.75 \% / 2.5 \% / 8 \%$, and $1 \% / 2.5 \% / 8 \%$. They were labeled NFC (0), NFC (0.25), NFC (0.5), NFC (0.75), and NFC (1), respectively.

\section{Characterization of the chemical structures of NFC and composite gels}

The NFC powder was characterized using a Fourier transform infrared (FT-IR) spectrometer (IR Prestige-21, Shimadzu International Trade Co., Ltd., Berlin, Germany). The sample was mixed with $\mathrm{KBr}$ (Sinopharm Chemical Reagent Co., Ltd. Shanghai, China) at a 1:100 ratio, and the pellet was pressed in a mold. The wave number range was $4000 \mathrm{~cm}^{-1}$ to $400 \mathrm{~cm}^{-1}$ and the resolution was $4 \mathrm{~cm}^{-1}$. The composite gels were characterized by attenuated total reflectance (ATR) mode after drying.

\section{Imaging of morphology and microstructure}

The hydrogel samples were immersed in $5 \% \mathrm{w} / \mathrm{v} \mathrm{CaCl}_{2}$ solution (Sinopharm Chemical Reagent Co., Ltd., Shanghai, China) for 24 h until they were completely crosslinked. Then, the swollen hydrogel samples were placed into a freeze dryer for $24 \mathrm{~h}$ after pre-freezing at $-20{ }^{\circ} \mathrm{C}$. The freeze-dried gels were observed by scanning electron 
microscopy (SEM, JSM-IT100; Japan Electronics Co., Ltd., Tokyo, Japan) operated with an acceleration voltage of $5 \mathrm{kV}$. Prior to examination, the gel samples were cut laterally and sputtered with gold (SC7620; Quorum Technologies Ltd., East Sussex, UK).

\section{Rheological measurements of inks and hydrogels}

The rheological properties of the biomaterial inks were measured using a rheometer (DISCOVERY HR-2, TA Instruments, NEW CASTLE, DE, USA) equipped with a coneplate with a diameter of $40 \mathrm{~mm}$ or $20 \mathrm{~mm}$. The biomaterial inks were tested before crosslinking and after crosslinking. To measure the viscosity, the matrix and the nanocomposite ink that was not crosslinked were loaded with steady rate sweeps within a shear rate range of $1 \mathrm{~s}^{-1}$ to $500 \mathrm{~s}^{-1}$. For the measurement of storage moduli $\left(G^{\prime}\right)$ and loss moduli $\left(G^{\prime \prime}\right)$ about cross-linked gels, frequency sweep tests were performed in the range of $0.1 \mathrm{rad} / \mathrm{s}$ to $100 \mathrm{rad} / \mathrm{s}$ at a constant strain rate of $1 \%$. All measurements were taken at a temperature of $37^{\circ} \mathrm{C}$. Further, the temperature dependence of $G^{\prime}$ and $G^{\prime \prime}$ were determined by temperature ramping of $10{ }^{\circ} \mathrm{C}$ to $50{ }^{\circ} \mathrm{C}$ with a heating rate of $1{ }^{\circ} \mathrm{C} / \mathrm{min}$ at a constant frequency of $1 \mathrm{rad} / \mathrm{s}$ and constant strain rate of $1 \%$.

\section{Mechanical testing of hydrogels}

The tensile properties of the hydrogels were measured using a tensile tester (JN-1, Zhejiang A\&F University, Hangzhou, China) at room temperature. Approximately $20 \mathrm{~mL}$ of the biomaterial inks were poured on square plastic petri dishes $(100 \mathrm{~mm} \times 100 \mathrm{~mm})$ and then cross-linked in $5 \mathrm{wt} \% \mathrm{CaCl}_{2}$ solution for $24 \mathrm{~h}$. The hydrogel samples were made into a dumbbell shape with a cutter before testing, and the tensile displacement rate was set to $20 \mathrm{~mm} / \mathrm{min}$ until the hydrogel samples were broken. The experiment was repeated five times for each group.

The compressive properties of the gels were measured with a universal testing machine (CMT6104, MTS Industrial Systems CO., LTD., Shenzheng, China) controlled by a microcomputer at room temperature. To determine the stress-strain curve, a strain displacement of $1 \mathrm{~mm} / \mathrm{min}$ was applied to the $\mathrm{Ca}^{2+}$ crosslinked cylindrical samples with a diameter of $15 \mathrm{~mm}$ and a height of $10 \mathrm{~mm}$, and the hydrogel samples were compressed until $50 \%$ compressive strain was reached. The experiment was repeated five times for each group.

\section{Swelling testing of hydrogels}

The swelling properties of the $\mathrm{Ca}^{2+}$ cross-linked hydrogels were tested by incubating in deionized water for $24 \mathrm{~h}$ at room temperature to reach equilibrium swelling, and the hydrogels were then gently blotted with filter paper and weighed. The dry weights of the gels were determined by drying the hydrogel in a vacuum oven at $40{ }^{\circ} \mathrm{C}$ until a constant weight was reached. The experiment was repeated five times for each group. The equilibrium swelling ratio $(S R)$ was calculated according to Eq. 1,

$$
S R(\%)=\left(W_{\mathrm{s}}-W_{\mathrm{d}}\right) / W_{\mathrm{d}} \times 100
$$

where $W_{\mathrm{s}}$ is the weight at swelling equilibrium $(\mathrm{g})$, and $W_{\mathrm{d}}$ is the weight after drying $(\mathrm{g})$.

\section{$3 D$ Printing of inks}

The biomaterial inks were printed using a desktop bioprinter (EFL-BP-6800; Suzhou Intelligent Manufacturing Research Institute, Suzhou, China). The bioprinter had a screw-driven X-Y-Z moving system, a pneumatic micro-extrusion system, and a 
temperature control system. Three-dimensional structures were printed after converting stereolithography (STL) files into G-code or writing G-code directly. To print a scaffold, the biomaterial inks were dispensed by the extrusion system to form hydrogel filaments with a conical nozzle $\left(0.26 \mathrm{~mm}\right.$ in size and a temperature of $\left.37^{\circ} \mathrm{C}\right)$, and the walking speed of the nozzle was $5 \mathrm{~mm} / \mathrm{s}$. Then, 3D structures were fabricated by the moving system on the printing platform $\left(5^{\circ} \mathrm{C}\right)$ for early stabilization. Finally, the $3 \mathrm{D}$ printed structures were soaked in a $5 \% \mathrm{w} / \mathrm{v} \mathrm{CaCl}_{2}$ solution for post stabilization at room temperature.

\section{RESULTS AND DISCUSSION}

\section{FT-IR Analysis of Nanocellulose and Composite Gels}

Figures $1 \mathrm{a}$ and $1 \mathrm{~b}$ show the uniform and stable NFC suspension after ultrasonic treatment and magnetic stirring, which did not precipitate after long-term storage. The FTIR spectra show the functional groups of the NFC and the composite gels. Figure 1c shows that the first absorbance band, which was strong and broad at $3800 \mathrm{~cm}^{-1}$ to $3000 \mathrm{~cm}^{-1}$. It was assigned to O-H stretching vibrations (Sultan and Mathew 2018), and the band at approximately $1641 \mathrm{c} \mathrm{m}^{-1}$ was attributed to the deformation vibrations of bound water molecules (Liu et al. 2015; Abouzeid et al. 2018; Sultan and Mathew 2018). The band at $2900 \mathrm{~cm}^{-1}$ belonged to the $\mathrm{C}-\mathrm{H}$ stretching vibrations of aliphatic chains, and the band around $1370 \mathrm{~cm}^{-1}$ belonged to $\mathrm{C}-\mathrm{H}$ bending vibrations. The characteristic absorbance bands between $800 \mathrm{~cm}^{-1}$ to $1400 \mathrm{~cm}^{-1}$ corresponded to the $\mathrm{C}-\mathrm{H}, \mathrm{O}-\mathrm{H}, \mathrm{C}-\mathrm{O}$, and $\mathrm{C}-\mathrm{O}-\mathrm{C}$ vibration on the glucosidic ring, which represent the fingerprint of cellulose (Liu et al. 2015b; Abouzeid et al. 2018).
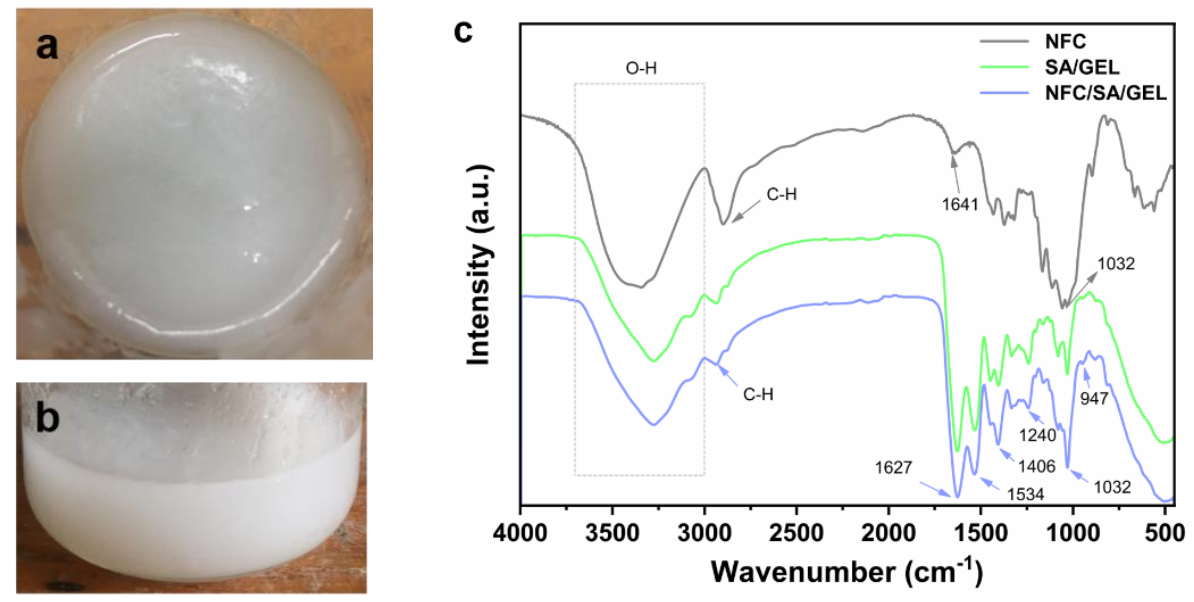

Fig. 1. Characterization of NFC: (a) NFC suspension vertical view; (b) NFC suspension side view; (c) FT-IR spectra of NFC, SA/GEL, and NFC/SA/GEL

For SA, the absorbance at 3000 to $3600 \mathrm{~cm}^{-1}$ was assigned to $\mathrm{O}-\mathrm{H}$ stretching vibrations, and the absorbance at around $2938 \mathrm{~cm}^{-1}$ was due to $\mathrm{C}-\mathrm{H}$ asymmetric and symmetric stretching of aliphatic chains. The absorption bands of the polysaccharide structure of sodium alginate appear at 1334, 1163, 1032 and $947 \mathrm{~cm}^{-1}$ corresponding to CO, C-C, C-O-C and C-O stretching (Naseri et al. 2016; Sultan and Mathew 2018). FT-IR spectrum of GEL found in spectrum focus mainly on peptide bands named Amide A and Amide I-III (Sultan and Mathew 2018). The characteristic absorption bands of Amide A at 
$3273 \mathrm{~cm}^{-1}$ was due to the intense Infrared absorption of $\mathrm{N}-\mathrm{H}$ stretching vibrations. Amide I band presented at around $1627 \mathrm{~cm}^{-1}$ belonged to $\mathrm{C}=\mathrm{O}$ and $\mathrm{C}-\mathrm{N}$ stretching vibrations, amide II band was at $1535 \mathrm{~cm}^{-1}$ assigned to N-H bending, and amide III band was at 1240 $\mathrm{cm}^{-1}$ attributed to C-N stretching vibrations (Khan et al. 2012; Stancu et al. 2013; Naseri et al. 2016; Sultan and Mathew 2018).

\section{Morphologies of Hydrogels}

Figure 2 shows the macroscopic morphology of the 5 groups of hydrogel samples with different NFC concentrations after crosslinking by $\mathrm{Ca}^{2+}$. Figure 2 shows that, as NFC concentration increased, the transparency of the hydrogel sample gradually decreased and it appeared milky white. Additionally, there were no visible agglomerates. The SEM images of the freeze-dried NFC (0) and NFC (0.75) gel samples are shown in Fig. 3. The freeze-dried hydrogel had a three-dimensional porous network structure that conformed to the typical characteristics of natural polymer hydrogels. For tissue engineering, the threedimensional porous sponge structure is conducive to cell growth and nutrient exchange. Figure 3a shows that the SA/GEL matrix gel had differently sized apertures and smooth aperture walls. In addition, the pore sizes tended to be more homogeneous, and the pore walls appeared to become rougher with the addition of NFC (Fig. 3b), which is considered favorable for cell adhesion and extracellular matrix (ECM) production (Naseri et al. 2016). In the process of freeze-drying, the ice crystals directly sublimated from the hydrogel samples under the vacuum, which resulted in a porous structure, and the pores reflected the original ice crystals (Wang et al. 2017; Jiang et al. 2018). The addition of NFC strengthened the structure of the hydrogels and caused the formation of ordered ice crystals, which resulted in more uniform pores.

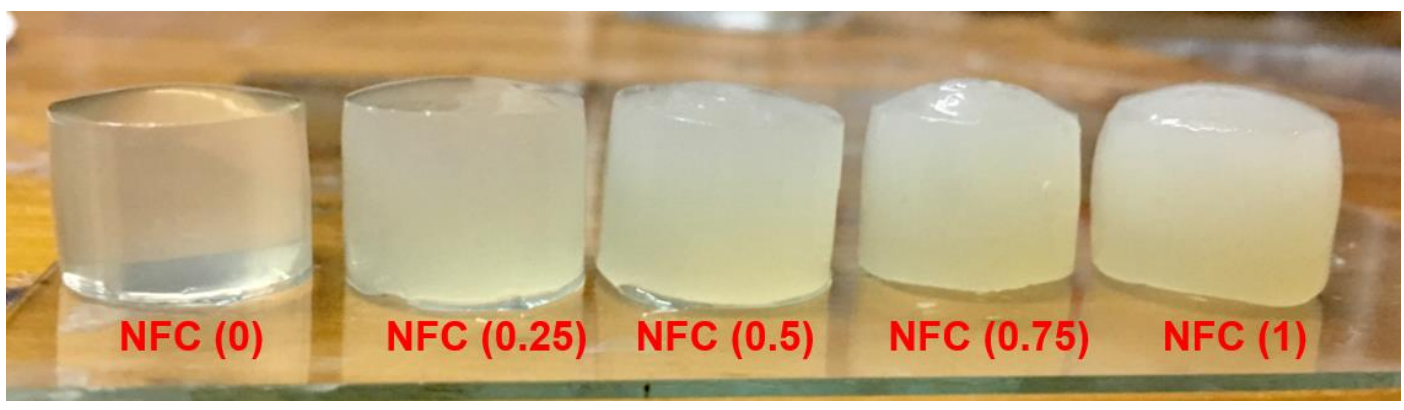

Fig. 2. The NFC/SA/GEL hydrogels at different NFC concentrations
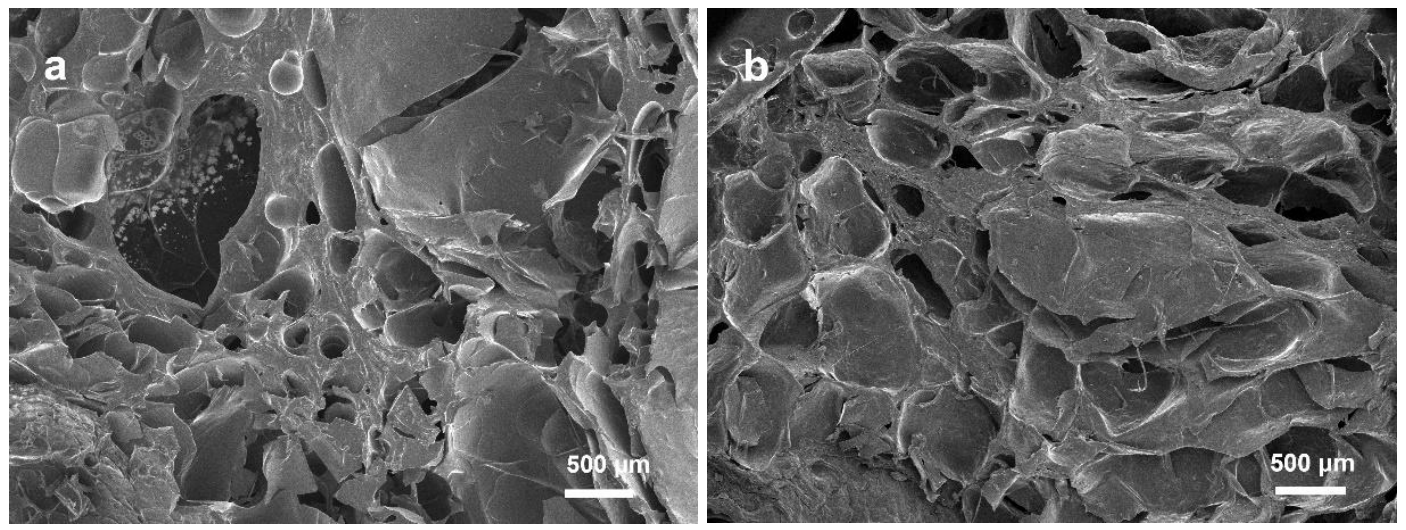

Fig. 3. The SEM images of the gels: (a) NFC (0); (b) NFC (0.75) 


\section{Rheological Properties}

To achieve good printability, biomaterial inks must be homogeneous and extrudable with a consistent flow while printing. Figure 4 shows that different ink compositions showed different flow behaviors before crosslinking with $\mathrm{Ca}^{2+}$ at $37{ }^{\circ} \mathrm{C}$. The same volume of SA/GEL inks and NFC/SA/GEL inks were moved into sample vials and then inverted and maintained for $30 \mathrm{~s}$. Figure 4a shows that the flow performances of the NFC/SA/GEL inks were noticeably lower than that of the SA/GEL ink. The viscosity of the inks changed after the NFC was added.

a

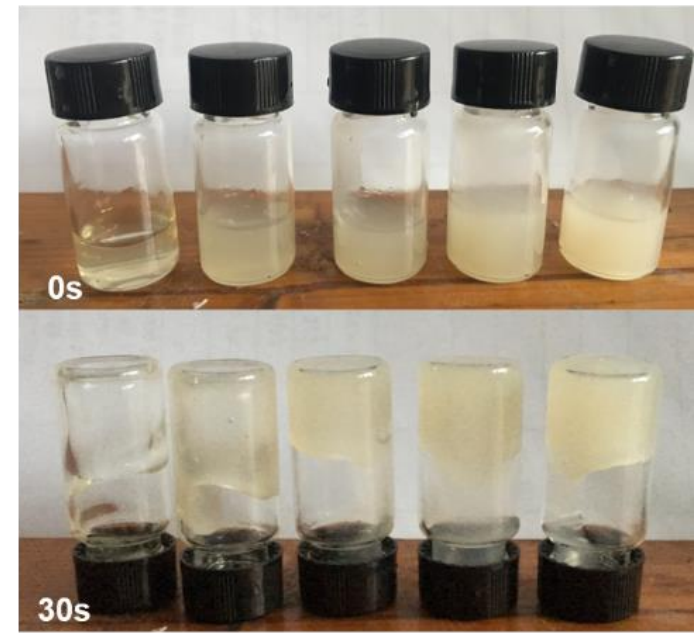

NFC (0) NFC (0.25) NFC (0.5) NFC (0.75) NFC (1)

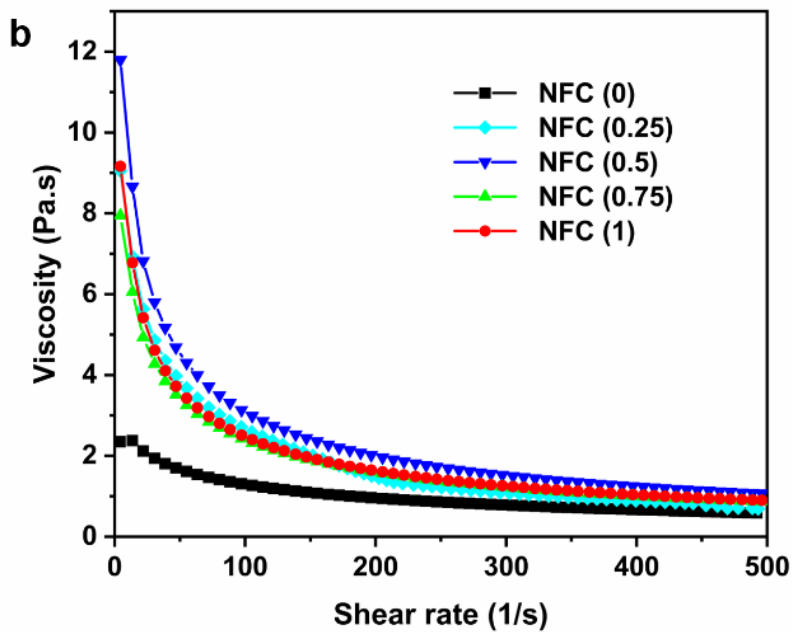

Fig. 4. The rheological properties of the NFC/SA/GEL ink at different NFC concentrations before $\mathrm{Ca}^{2+}$ cross-linking: (a) Flow behavior of NFC (0), NFC (0.25), NFC (0.5), NFC (0.75), and NFC (1); (b) The viscosity-shear rate

For extrusion-based 3D printing, ink printability means that, during the printing process, the viscosity of the ink decreases rapidly when subjected to shear stress in the cylinder. Therefore, the ink was easily extruded from the nozzle. Then, when the ink was extruded out of the nozzle and the shear stress on the nozzle disappeared, most of the viscosity was quickly restored, which was beneficial to the formation of the support structure and maintenance of the mechanical strength (Håkansson et al. 2016; Heggset et al. 2018). This phenomenon was called "viscosity recovery." During the printing process of bio-ink, the ink underwent the phenomena of "shear thinning" and "viscosity recovery," which are also known as thixotropic behavior (Chinga-Carrasco 2018).

As studied by other researchers (Markstedt et al. 2015; Tabriz et al. 2015; Shin et al. 2017; Heggset et al. 2018), NFC itself shows a shear-thinning behavior that was required for the extrusion-based printing process. Before crosslinking with $\mathrm{Ca}^{2+}$, the viscosity properties of NFC (0), NFC (0.25), NFC (0.5), NFC (0.75), and NFC (1) samples at $37^{\circ} \mathrm{C}$ are shown in Fig. $4 \mathrm{~b}$, which shows that the addition of NFC noticeably increased the viscosity of biological inks under a zero or low shear rate. Further, the viscosity of NFC/SA/GEL bio-inks decreased rapidly as the shear rate was increased. This phenomenon indicated that the NFC/SA/GEL bio-inks presented a clear shear-thinning behavior (Markstedt et al. 2015; Müller et al. 2017), which was attributed to the temporary destruction of the physical interactions between the macromolecules and the alignment of the polymer chains caused by a high shear rate (Ureña-Benavides et al. 2011; Jessop et al. 2019). In addition, it can be found that, as shear rate was increased, the influence of NFC 
on viscosity of the ink gradually decreased, which indicated that the weak bond failure rate in the system reached an equilibrium value when the shear rate reached a certain value. Further, due to the highly active surface of the nanoparticles, NFC was prone to agglomeration (Kalia et al. 2011). In addition, Figure 4b shows that excessive NFC content reduced the viscosity of the ink. This was due to the partial agglomeration of NFC, which reduced the number of effective NFC points in the matrix ink and affected the structural order.

The results of frequency sweeps (Fig. 5a) showed the $G$ ' and $G$ ', values of crosslinked bio-inks, which represented the elasticity and viscosity of the sample, respectively (Ureña-Benavides et al. 2011; Heggset et al. 2018). Figure 5a shows that five different groups of bio-inks had several characteristics in common, i.e., a higher value of $G$ ' than $G$ ', no crossover point, and a constant slight increase of $G$ ' and $G$ ', with increased frequency. The values of $\mathrm{G}^{\prime}$ and $G$ ' can determine the gel-sol state of the material system. A higher value of $G^{\prime}$ than $G^{\prime}$ ' indicated that the inks exhibited a gelled structure, thereby facilitating excellent shape stability and fidelity (Chung et al. 2013; Heggset et al. 2018; Sultan et al. 2018). Additionally, Fig. 5a shows that the $G$ ' and $G$ '' values of NFC/SA/GEL hydrogels were much higher than those of pure SA/GEL hydrogels. This occurred because the addition of NFC increased intermolecular entanglement. However, the $G$ ' value of the hydrogel did not change linearly with the NFC concentration. When NFC concentration was higher than $0.75 \% \mathrm{w} / \mathrm{v}$, the storage modulus of the hydrogel decreased, which indicated that NFC had agglomerated in the matrix hydrogel. Thus, in the process of elastic modulus recovery, the internal stress transfer rate was inconsistent, and the transfer efficiency was low, which resulted in the decline of the macroscopic storage modulus.

Finally, temperature sweeps were performed to determine the gel-sol state of bioinks after crosslinking with $\mathrm{Ca}^{2+}$. Figure 5b shows that $G$ ' was always higher than $G$ ', at $10{ }^{\circ} \mathrm{C}$ to $50{ }^{\circ} \mathrm{C}$, which indicated that the hydrogel network remained stable, and the system was always in a solid-like hydrogel shape after crosslinking with $\mathrm{Ca}^{2+}$ (Abouzeid et al. 2018).
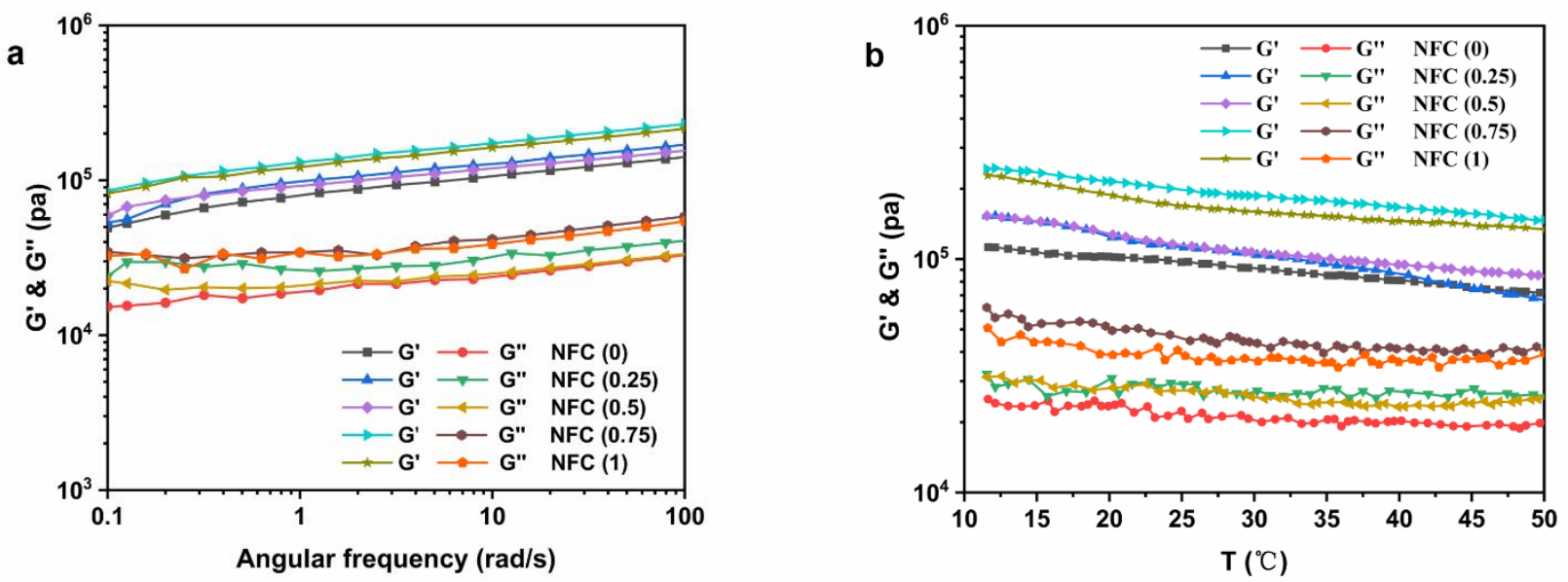

Fig. 5. The rheological properties of the NFC/SA/GEL ink at different NFC concentrations after $\mathrm{Ca}^{2+}$ crosslinking: (a) The storage modulus $\left(G^{\prime}\right)$ and loss modulus ( $\left.G^{\prime \prime}\right)$-angular frequency of NFC (0), NFC (0.25), NFC (0.5), NFC (0.75), and NFC (1); (b) The storage modulus (G') and loss modulus (G”) temperature of NFC (0), NFC (0.25), NFC (0.5), NFC (0.75), and NFC (1) 


\section{Mechanical Analysis}

The mechanical properties of the composite hydrogel materials depend on both the enhancement properties of the nano-filler and the interaction between the nano-filler, the matrix, and the dispersion in the matrix (Chimene et al. 2016; Jaiswal et al. 2016).

Figure 6 shows the casted hydrogel samples used for the tensile test (Fig. 6a) and the compression test (Fig. 6b) after crosslinking with $\mathrm{Ca}^{2+}$. The addition of NFC increased the Young's modulus of the hydrogel (Fig. 7a). Under the same tensile stress, the deformation of the hydrogel sample was smaller.

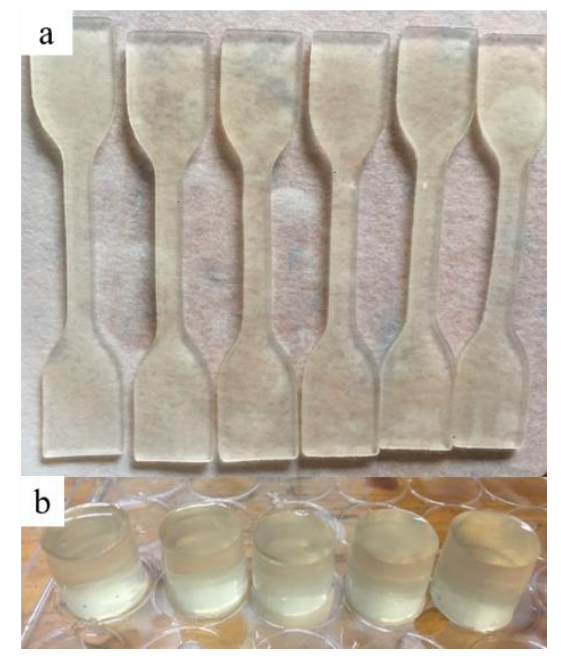

Fig. 6. The mechanical property testing gel samples: (a) Tensile test samples; (b) Compression test samples
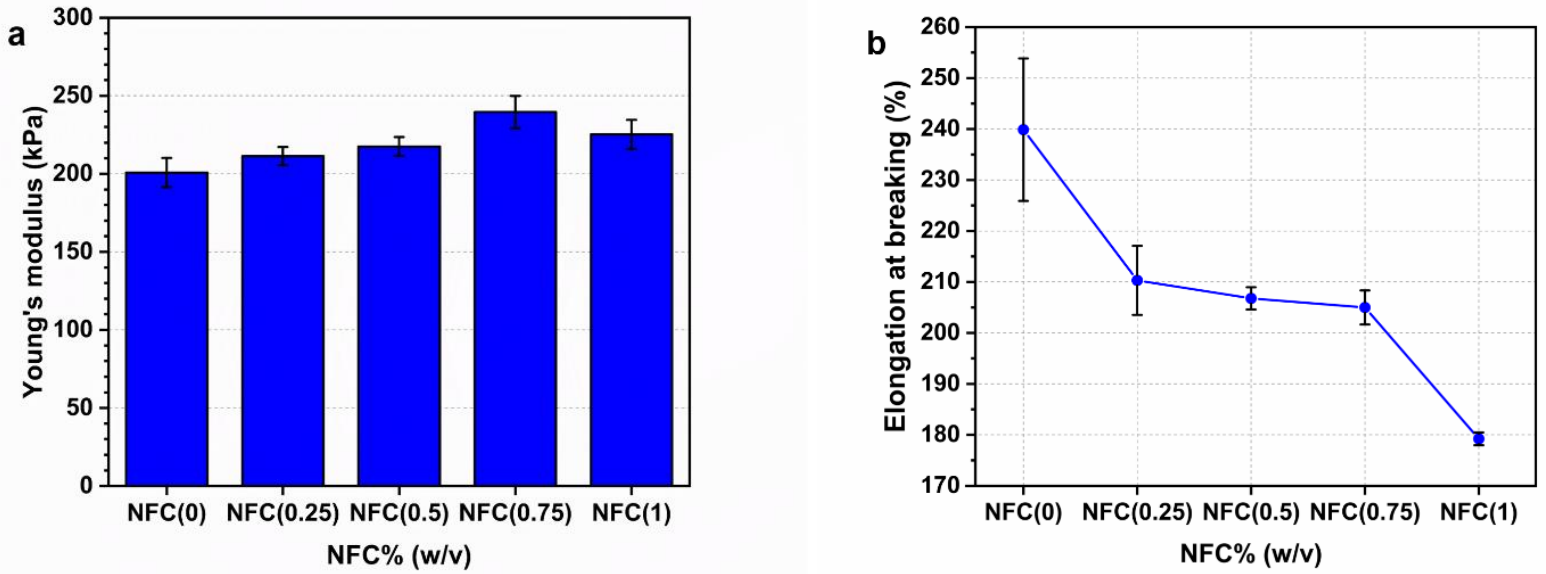

Fig. 7. The mechanical properties of the NFC/SA/GEL hydrogels at different NFC concentrations: (a) Young's modulus; (b) Elongation at breaking

Figure 8A shows that when the deformation amount was $50 \%$, the compression strength of the composite hydrogel containing $0.75 \% \mathrm{w} / \mathrm{v}$ NFC was $320 \mathrm{kPa}$, whereas that of the SA/GEL matrix hydrogel was $196 \mathrm{kPa}$ (Fig. 8a). As the addition of NFC enhanced the intermolecular entanglement and increased the intermolecular hydrogen bond (Li et al. 2014; Jiang et al. 2018), the NFC/SA/GEL hydrogels with different NFC concentrations added could withstand greater stress under the same strain. Therefore, they were superior 
to the SA/GEL hydrogels in stiffness. However, the mechanical properties of NFC (1) were worse than those of NFC (0.75), which was similar to the results from the rheological analysis. This was because the structural ordering of the hydrogels was destroyed by the agglomeration of excessive NFC, which resulted in increased stress concentration during the tensile or compression test. In contrast, the addition of NFC had a negative impact on the elongation at break and compression yield strain of the hydrogels (Fig. 7a and Fig. 8a). This was because NFC was prone to agglomeration, and these agglomeration parts had poor tensile and compressive resistance. Once the internal stress reached a certain value, cracks occurred, and the hydrogel structure was damaged (Jiang et al. 2018). Of the varied NFC concentrations, NFC (0.75) had the best mechanical properties.
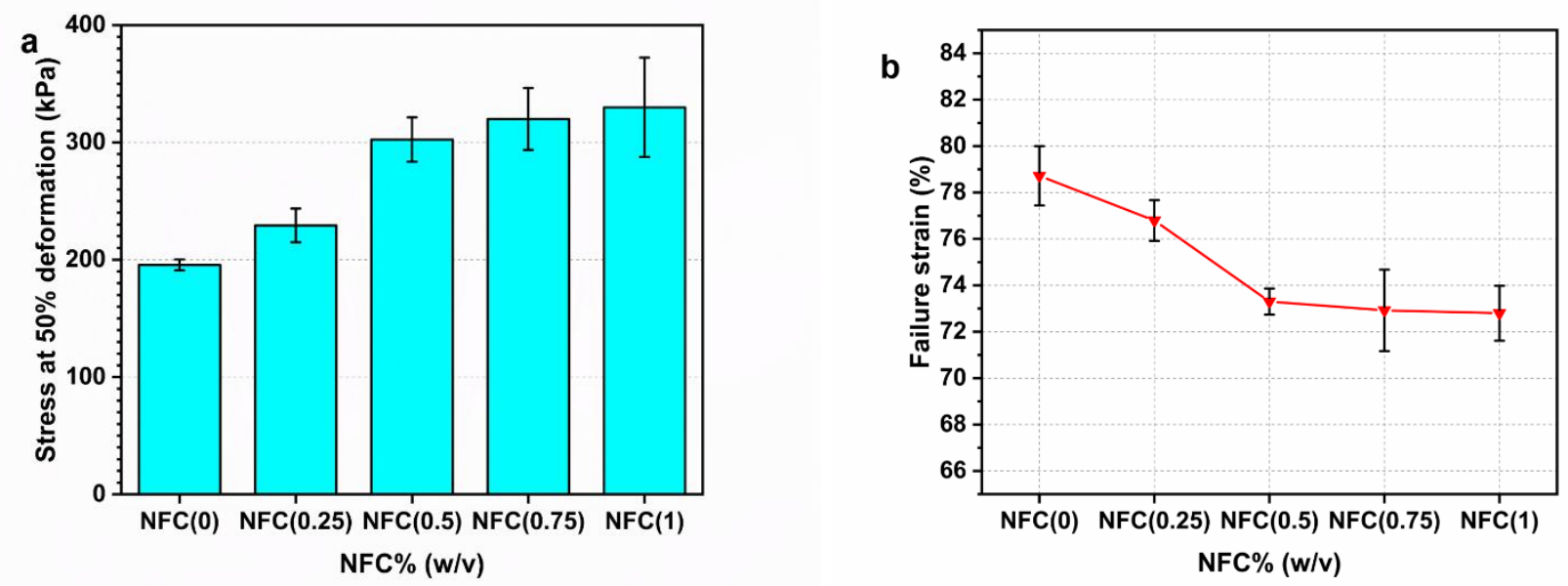

Fig. 8. The mechanical properties of the NFC/SA/GEL hydrogels at different NFC concentrations: (a) The compressive stress withstanding when the deformation amount was 50\%; (b) Compression yield strain

\section{Swelling Behavior}

Figure 9 shows the equilibrium swelling rate of the NFC/SA/GEL hydrogels at different NFC concentrations in deionized water for $24 \mathrm{~h}$.

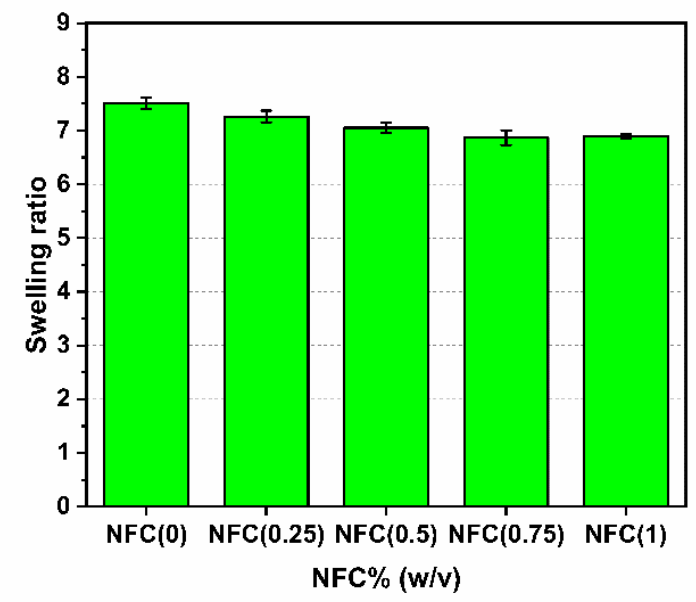

Fig. 9. The swelling properties of the NFC/SA/GEL hydrogels at different NFC concentrations 
The swelling ratio of the hydrogels decreased with the addition of NFC, which was because the intermolecular hydrogen bond interaction increased, and the intermolecular entanglement strengthened. Therefore, the intermolecular interaction became more compact. In addition, after mixing NFC with SA/GEL, NFC partially occupied the spaces of the hydrogel network, which resulted in a relatively dense hydrogel structure (Gao et al. 2019), so the swelling abilities of NFC/SA/GEL hydrogels were inferior to that of the porous SA/GEL hydrogel (Wang et al. 2016). However, there was no noticeable difference in the swelling rate of hydrogels in different groups.

\section{Printability Analysis}

Figure 11 shows the $3 \mathrm{D}$ printed samples before cross-linking in a $5 \% \mathrm{w} / \mathrm{v} \mathrm{CaCl}_{2}$ solution, and the shape fidelity was largely maintained. Figure 11a shows a photo of SA/GEL ink deposited on a printing platform after being extruded through a nozzle. The outer part of the SA/GEL hydrogel was more prone to collapse, especially when there was condensation on the printing platform. With the addition of NFC, the collapse of hydrogel was noticeably alleviated, and the filaments deposited on the printing platform were clearer.

During the stacking process, the filaments diffused and dropped to the height direction because of gravity, which resulted in the difference between the theoretical model and the actual model. The difference was particularly large for printing height. In this study, to evaluate the fidelity of hydrogels in height, the hollow model shown in Fig. 10a was printed with 5 groups of bio-inks and stacked layer-by-layer until the structure collapsed or the filaments were broken, and the maximum number of printed layers was recorded (Fig. 10c).
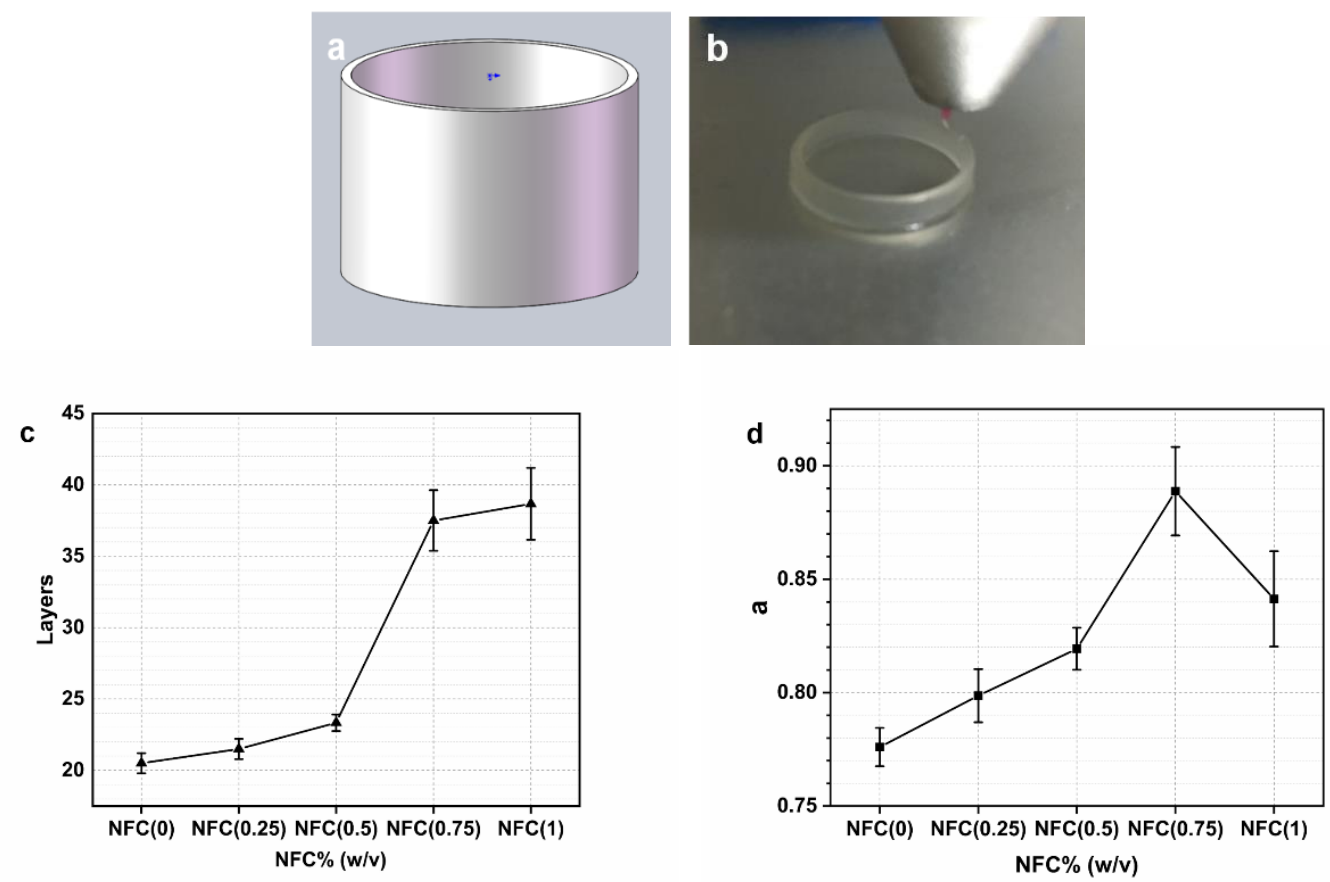

Fig. 10. Printability analysis of the NFC/SA/GEL inks with regard to the stacking process: (a) Theoretical model of 3D printing; (b) Actual model; (c) The maximum number of printing layers at the height of the tube; (d) Effect of the NFC concentration on $\alpha$ 


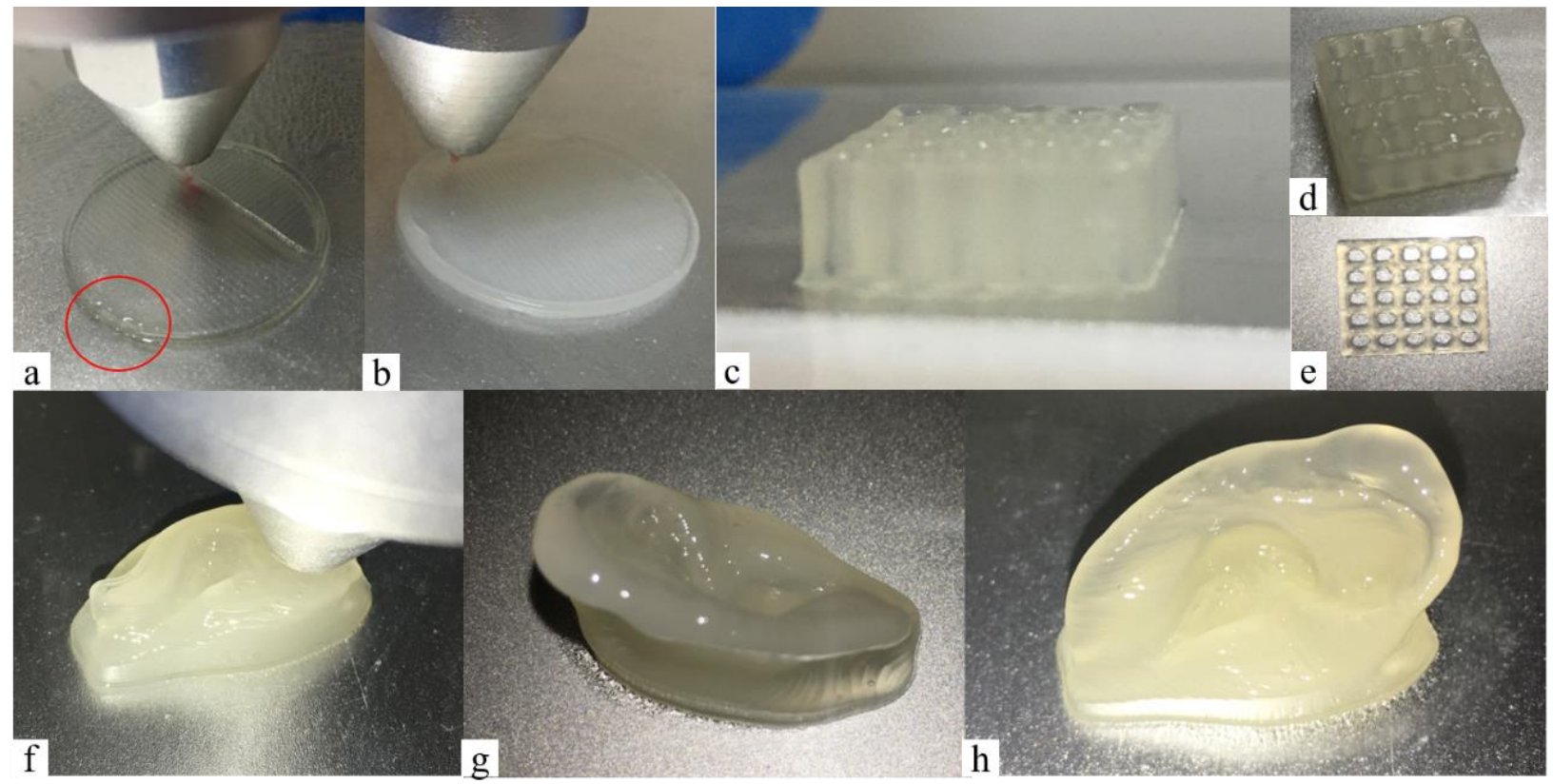

Fig. 11. Photographs of the printed scaffolds with various shapes: (a) $3 D$ printing of SA/GEL bioink; (b) 3D printing of NFC/SA/GEL bio-ink; (c) A multilayer grid-shaped bracket; (d) A multilayer grid-shaped bracket; (e) A single layer grid-shaped bracket; (f) A human bionic being printed; (g) A human bionic ear; (h) A human bionic ear

The $\alpha$ (indicator of sinking degree) value was calculated according to Eq. 2,

$$
\alpha=H / H_{0}
$$

where $H$ was the actual height $(\mathrm{mm})$ and $H_{0}$ was the theoretical height $(\mathrm{mm})$.

As shown in Fig. 10c and Fig. 10d, the addition of NFC increased the maximum number of printed layers and reduced the degree of sinking, which directly increased its deformation resistance. The results showed that when NFC was added at $0.75 \% \mathrm{w} / \mathrm{v}$, printing performance was optimal.

Finally, the NFC (0.75) bio-ink scaffolds were successfully printed with various shapes, such as a grid-shaped bracket (Fig. 11c, Fig. 11d, and Fig. 11e) and a human bionic ear (Fig. 11f, Fig. 11g, and Fig. 11h), which confirmed that the printed scaffolds maintained high shape fidelity and did not collapse or lose their shape during the printing process due to the viscosity of the ink (Markstedt et al. 2015; Dai et al. 2019; Gao et al. 2019).

To evaluate the change in shape and size after crosslinking with $\mathrm{Ca}^{2+}$, five groups of bio-ink gel samples were studied before crosslinking and after $1 \mathrm{~h}$ of crosslinking (Markstedt et al. 2015). Figure 11 shows a change in shape and size, which was indicated by the $\beta$ value. The $\beta$ was calculated according to Eq. 3,

$$
\beta=\left(D_{\mathrm{b}}-D_{\mathrm{a}}\right) / D_{\mathrm{b}} \times 100 \%
$$

where $D_{\mathrm{b}}$ is the size $(\mathrm{mm})$ before crosslinking with $\mathrm{Ca}^{2+}$ and $D_{\mathrm{a}}$ is the size $(\mathrm{mm})$ after crosslinking with $\mathrm{Ca}^{2+}$.

Figure 12b shows that, as NFC concentration increased, the rate of size change of the hydrogels before and after crosslinking gradually decreased. Therefore, the addition of NFC improved the shape fidelity of hydrogel after crosslinking with $\mathrm{Ca}^{2+}$. 
a

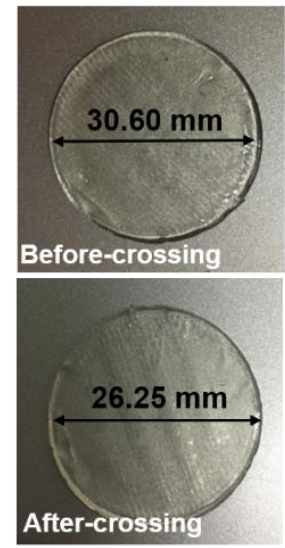

NFC (0)
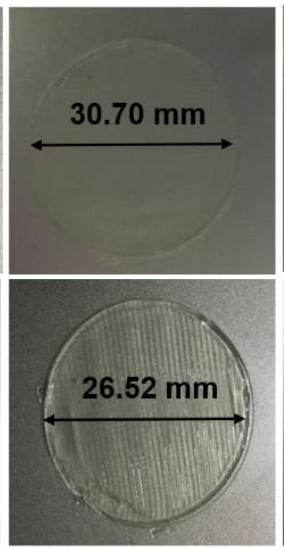

NFC (0.25)

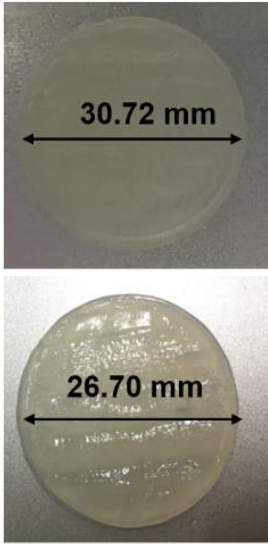

NFC (0.5)

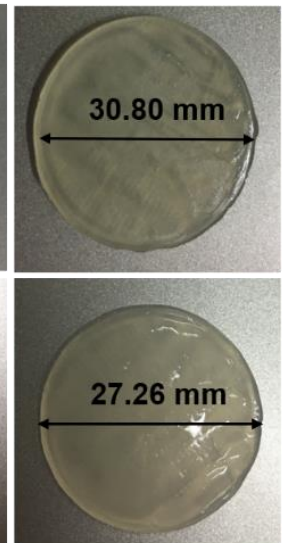

NFC (0.75)

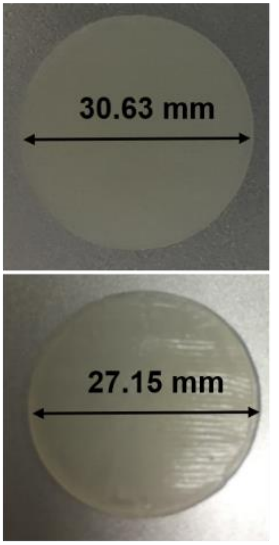

NFC (1)

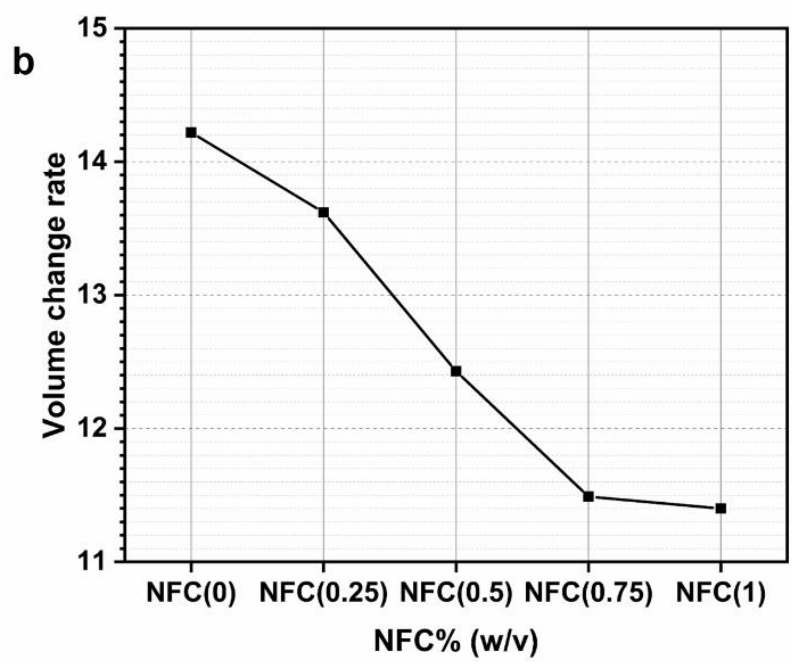

Fig. 12. Size changes of the hydrogels after cross-linking with $\mathrm{Ca}^{2+}$; (a) Measurement of size before and after crosslinking; (b) Effect of the NFC concentration on $\beta$

\section{CONCLUSIONS}

1. The rheological results showed that a small amount of NFC caused the inks to exhibit shear thinning and rapid gelling. The NFC/SA/GEL inks had better printability than the SA/GEL matrix ink.

2. Various structures with high fidelity and stability were easily printed due to the thixotropic property of NFC. The stability and fidelity of structures were reflected both in the decrease of diffusion and sinking of filaments during the printing process and in the improvement of the fidelity of the structure dimensions after being crosslinked with $\mathrm{Ca}^{2+}$.

3. The addition of NFC strengthened the structure and improved the mechanical properties of the hydrogels because the NFC acted as a structural support. When under the same strain, the NFC/SA/GEL composite hydrogels had greater tensile and compressive stress. However, NFC had a negative impact on the elongation at break and compression yield strain of the hydrogels. 
4. The NFC was prone to agglomeration. The results showed that NFC (0.75) had optimal performance.

\section{ACKNOWLEDGMENTS}

This work was supported by the Planning Project of Application Research for Public Service Technology of Zhejiang Province (LGG18E060002), the Zhejiang Provincial Collaborative Innovation Center for Bamboo Resources and High-efficiency Utilization (2017ZZY2-15), and the Opening Project of Zhejiang Province Key Laboratory for Digital Design and Intelligent Manufacturing of Cultural Characteristics and Creative Products (ZD201803).

\section{REFERENCES CITED}

Aarstad, O., Heggset, E. B., Pedersen, I. S., Bjørnøy, S. H., Syverud, K., and Strand, B. L. (2017). "Mechanical properties of composite hydrogels of alginate and cellulose nanofibrils," Polymers 9(8), Article number 378. DOI: 10.3390/polym9080378

Abouzeid, R. E., Khiari, R., Beneventi, D., and Dufresne, A. (2018). "Biomimetic mineralization of three-dimensional printed alginate/TEMPO-oxidized cellulose nanofibril scaffolds for bone tissue engineering," Biomacromolecules 19(11), 44424452. DOI: 10.1021/acs.biomac.8b01325

Ahrem, H., Pretzel, D., Endres, M., Conrad, D., Courseau, J., Müller, H., Jaeger, R., Kaps, C., Klemm, D. O., and Kinne, R. W. (2014). "Laser-structured bacterial nanocellulose hydrogels support ingrowth and differentiation of chondrocytes and show potential as cartilage implants," Acta Biomaterialia 10(3), 1341-1353. DOI: 10.1016/j.actbio.2013.12.004

Carrow, J. K., and Gaharwar, A. K. (2015). "Bioinspired polymeric nanocomposites for regenerative medicine," Macromolecular Chemistry and Physics 216(3), 248-264. DOI: $10.1002 / \mathrm{macp} .201400427$

Chimene, D., Lennox, K. K., Kaunas, R. R., and Gaharwar, A. K. (2016). “Advanced bioinks for 3D printing: A materials science perspective," Annals of Biomedical Engineering 44(6), 2090-2102. DOI: 10.1007/s10439-016-1638-y

Chinga-Carrasco, G. (2018). "Potential and limitations of nanocelluloses as components in biocomposite inks for three-dimensional bioprinting and for biomedical devices," Biomacromolecules 19(3), 701-711. DOI: 10.1021/acs.biomac.8b00053

Chung, J. H. Y., Naficy, S., Yue, Z., Kapsa, R., Quigley, A., Moulton, S. E., and Wallace, G. G. (2013). "Bio-ink properties and printability for extrusion printing living cells," Biomaterials Science 1(7), 763-773. DOI: 10.1039/c3bm00012e

Dai, L., Cheng, T., Duan, C., Zhao, W., Zhang, W., Zou, X., Aspler, J., and Ni, Y. (2019). "3D printing using plant-derived cellulose and its derivatives: A review," Carbohydrate Polymers 203, 71-86. DOI: 10.1016/j.carbpol.2018.09.027

Dash, R., Foston, M., and Ragauskas, A. J. (2013). "Improving the mechanical and thermal properties of gelatin hydrogels cross-linked by cellulose nanowhiskers," Carbohydrate Polymers 91(2), 638-645. DOI: 10.1016/j.carbpol.2012.08.080

Derby, B. (2012). "Printing and prototyping of tissues and scaffolds," Science 338(6109), 921-926. DOI: 10.1126/science. 1226340 
Du, H., Liu, W., Zhang, M., Si, C., Zhang, X., and Li, B. (2019). "Cellulose nanocrystals and cellulose nanofibrils based hydrogels for biomedical applications," Carbohydrate Polymers 209, 130-144. DOI: 10.1016/j.carbpol.2019.01.020

Florczyk, S. J., Leung, M., Li, Z., Huang, J. I., Hopper, R. A., and Zhang, M. (2013). "Evaluation of three-dimensional porous chitosan-alginate scaffolds in rat calvarial defects for bone regeneration applications," Journal of Biomedical Materials Research Part A 101(10), 2974-2983. DOI: 10.1002/jbm.a.34593

Gaharwar, A. K., Peppas, N. A., and Khademhosseini, A. (2014). "Nanocomposite hydrogels for biomedical applications," Biotechnology and Bioengineering 111(3), 441-453. DOI: 10.1002/bit.25160

Gao, G., Schilling, A. F., Yonezawa, T., Wang, J., Dai, G., and Cui, X. (2014). "Bioactive nanoparticles stimulate bone tissue formation in bioprinted threedimensional scaffold and human mesenchymal stem cells," Biotechnology Journal 9(10), 1304-1311. DOI: 10.1002/biot.201400305

Gao, Q., Niu, X., Shao, L., Zhou, L., Lin, Z., Sun, A., Fu, J., Chen, Z., Hu, J., Liu, Y., et al. (2019). "3D printing of complex GelMA-based scaffolds with nanoclay," Biofabrication 11(3), Article ID 035006. DOI: 10.1088/1758-5090/ab0cf6

Håkansson, K. M. O., Henriksson, I. C., de la Peña Vázquez, C., Kuzmenko, V., Markstedt, K., Enoksson, P., and Gatenholm, P. (2016). "Solidification of 3D printed nanofibril hydrogels into functional 3D cellulose structures," Advanced Materials Technologies 1(7), Article ID 1600096. DOI: 10.1002/admt.201600096

He, Y., Yang, F., Zhao, H., Gao, Q., Xia, B., and Fu, J. (2016). "Research on the printability of hydrogels in 3D bioprinting," Scientific Reports 6, Article ID 29977. DOI: $10.1038 /$ srep29977

Heggset, E. B., Strand, B. L., Sundby, K. W., Simon, S., Chinga-Carrasco, G., and Syverud, K. (2018). "Viscoelastic properties of nanocellulose based inks for 3D printing and mechanical properties of NFC/alginate biocomposite gels," Cellulose 26(1), 581-595. DOI: 10.1007/s10570-018-2142-3

Jaiswal, M. K., Xavier, J. R., Carrow, J. K., Desai, P., Alge, D., and Gaharwar, A. K. (2016). "Mechanically stiff nanocomposite hydrogels at ultralow nanoparticle content," ACS Nano 10(1), 246-256. DOI: 10.1021/acsnano.5b03918

Jessop, Z. M., Al-Sabah, A., Gao, N., Kyle, S., Thomas, B., Badiei, N., Hawkins, K., and Whitaker, I. S. (2019). "Printability of pulp derived crystal, fibril and blend nanocellulose-alginate bioinks for extrusion 3D bioprinting," Biofabrication 11(4), Article ID 045006. DOI: 10.1088/1758-5090/ab0631

Jiang, Y., Xv, X., Lu, D., Yang, Z., Zhang, Q., Shi, H., Zhao, G., and Zhou, J. (2018). "Preparation of cellulose nanofiber-reinforced gelatin hydrogel and optimization for 3D printing applications," BioResources 13(3), 5909-5924. DOI: 10.15376/biores.13.3.5909-5924

Kalia, S., Dufresne, A., Cherian, B. M., Kaith, B. S., Avérous, L., Njuguna, J., and Nassiopoulos, E. (2011). "Cellulose-based bio- and nanocomposites: A review," International Journal of Polymer Science 2011, 1-35. DOI: 10.1155/2011/837875

Khan, A., Khan, R. A., Salmieri, S., Le Tien, C., Riedl, B., Bouchard, J., Chauve, G., Tan, V., Kamal, M. R., and Lacroix, M. (2012). "Mechanical and barrier properties of nanocrystalline cellulose reinforced chitosan based nanocomposite films," Carbohydr. Polym. 90(4), 1601-1608. DOI: 10.1016/j.carbpol.2012.07.037 
Kirchmajer, D. M., Gorkin, III, R., and in het Panhuis, M. (2015). "An overview of the suitability of hydrogel-forming polymers for extrusion-based 3D-printing," Journal of Materials Chemistry B 3(20), 4105-4117. DOI: 10.1039/c5tb00393h

Lee, K. Y., and Mooney, D. J. (2012). "Alginate: Properties and biomedical applications," Progress in Polymer Science 37(1), 106-126. DOI:

10.1016/j.progpolymsci.2011.06.003

Li, W., Guo, R., Lan, Y., Zhang, Y., Xue, W., and Zhang, Y. (2014). "Preparation and properties of cellulose nanocrystals reinforced collagen composite films," Journal of Biomedical Materials Research Part A 102(4), 1131-1139. DOI: 10.1002/jbm.a.34792

Liu, J., Willför, S., and Xu, C. (2015a). "A review of bioactive plant polysaccharides: Biological activities, functionalization, and biomedical applications," Bioactive Carbohydrates and Dietary Fibre 5(1), 31-61. DOI: 10.1016/j.bcdf.2014.12.001

Liu, P., Borrell, P. F., Božič, M., Kokol, V., Oksman, K., and Mathew, A. P. (2015b). "Nanocelluloses and their phosphorylated derivatives for selective adsorption of $\mathrm{Ag}^{+}$, $\mathrm{Cu}^{2+}$ and $\mathrm{Fe}^{3+}$ from industrial effluents," Journal of Hazardous Materials 294, $177-$ 185. DOI: 10.1016/j.jhazmat.2015.04.001

Liu, Y., and Chan-Park, M. B. (2010). "A biomimetic hydrogel based on methacrylated dextran-graft-lysine and gelatin for 3D smooth muscle cell culture," Biomaterials 31(6), 1158-1170. DOI: 10.1016/j.biomaterials.2009.10.040

Luo, Y., Li, Y., Qin, X., and Wa, Q. (2018). "3D printing of concentrated alginate/gelatin scaffolds with homogeneous nano apatite coating for bone tissue engineering," Materials \& Design 146, 12-19. DOI: 10.1016/j.matdes.2018.03.002

Mandrycky, C., Wang, Z., Kim, K., and Kim, D. H. (2016). "3D bioprinting for engineering complex tissues," Biotechnology Advances 34(4), 422-434. DOI: 10.1016/j.biotechadv.2015.12.011

Markstedt, K., Mantas, A., Tournier, I., Martinez Ávila, H., Hägg, D., and Gatenholm, P. (2015). "3D bioprinting human chondrocytes with nanocellulose-alginate bioink for cartilage tissue engineering applications," Biomacromolecules 16(5), 1489-1496.

DOI: 10.1021/acs.biomac.5b00188

Müller, M., Öztürk, E., Arlov, Ø., Gatenholm, P., and Zenobi-Wong, M. (2017). "Alginate sulfate-nanocellulose bioinks for cartilage bioprinting applications," Annals of Biomedical Engineering 45(1), 210-223. DOI: 10.1007/s10439-016-1704-5

Naseri, N., Deepa, B., Mathew, A. P., Oksman, K., and Girandon, L. (2016). "Nanocellulose-based interpenetrating polymer network (IPN) hydrogels for cartilage applications," Biomacromolecules 17(11), 3714-3723. DOI: 10.1021/acs.biomac.6b01243

Nguyen, D., Hägg, D. A., Forsman, A., Ekholm, J., Nimkingratana, P., Brantsing, C., Kalogeropoulos, T., Zaunz, S., Concaro, S., Brittberg, M., and Lindahl, A., et al. (2017). "Cartilage tissue engineering by the 3D bioprinting of iPS cells in a nanocellulose/alginate bioink," Scientific Reports 7(1), Article number 658. DOI: 10.1038/s41598-017-00690-y

Ooi, S. Y., Ahmad, I., and Amin, M. C. I. M. (2016). "Cellulose nanocrystals extracted from rice husks as a reinforcing material in gelatin hydrogels for use in controlled drug delivery systems," Industrial Crops and Products 93, 227-234. DOI: 10.1016/j.indcrop.2015.11.082

Shin, S., Park, S., Park, M., Jeong, E., Na, K., Youn, H. J., and Hyun, J. (2017). "Cellulose nanofibers for the enhancement of printability of low viscosity gelatin 
derivative," BioResources 12(2), 2941-2954. DOI: 10.15376/biores.12.2.2941-2954

Siqueira, G., Kokkinis, D., Libanori, R., Hausmann, M. K., Gladman, A. S., Neels, A., Tingaut, P., Zimmermann, T., Lewis, J. A., and Studart, A. R. (2017). "Cellulose nanocrystal inks for 3d printing of textured cellular architectures," Advanced Functional Materials 27(12), Article ID 1604619. DOI: 10.1002/adfm.201604619

Stancu, I.-C., Lungu, A., Dragusin, D. M., Vasile, E., Damian, C., and Iovu, H. (2013). "Porous gelatin-alginate-polyacrylamide scaffolds with interpenetrating network structure: Synthesis and characterization," Soft Materials11(4), 384-393. DOI: $10.1080 / 1539445 x .2011 .642091$

Sultan, S., and Mathew, A. P. (2018). "3D printed scaffolds with gradient porosity based on a cellulose nanocrystal hydrogel," Nanoscale 10(9), 4421-4431. DOI: 10.1039/c7nr08966j

Tabriz, A. G., Hermida, M. A., Leslie, N. R., and Shu, W. (2015). "Three-dimensional bioprinting of complex cell laden alginate hydrogel structures," Biofabrication 7(4), Article ID 045012. DOI: 10.1088/1758-5090/7/4/045012

Thakur, T., Xavier, J. R., Cross, L., Jaiswal, M. K., Mondragon, E., Kaunas, R., and Gaharwar, A. K. (2016). "Photocrosslinkable and elastomeric hydrogels for bone regeneration," Journal of Biomedical Materials Research Part A 104(4), 879-888. DOI: 10.1002/jbm.a.35621

Ureña-Benavides, E. E., Ao, G., Davis, V. A., and Kitchens, C. L. (2011). "Rheology and phase behavior of lyotropic cellulose nanocrystal suspensions," Macromolecules 44(22), 8990-8998. DOI: 10.1021/ma201649f

Wang, K., Nune, K. C., and Misra, R. D. K. (2016). "The functional response of alginategelatin-nanocrystalline cellulose injectable hydrogels toward delivery of cells and bioactive molecules," Acta Biomateriala 36, 143-151. DOI:

10.1016/j.actbio.2016.03.016

Wang, W., Zhang, X., Teng, A., and Liu, A. (2017). "Mechanical reinforcement of gelatin hydrogel with nanofiber cellulose as a function of percolation concentration," International Journal of Biological Macromolecules 103, 226-233. DOI:

10.1016/j.ijbiomac.2017.05.027

Xu, W., Molino, B. Z., Cheng, F., Molino, P. J., Yue, Z., Su, D., Wang, X., Willfor, S., $\mathrm{Xu}, \mathrm{C}$., and Wallace, G. G. (2019). "On low-concentration inks formulated by nanocellulose assisted with gelatin methacrylate (GelMA) for 3D printing toward wound healing application," ACS Applied Materials and Interfaces 11(9), 8838-8848. DOI: $10.1021 /$ acsami.8b21268

Yue, K., Trujillo-de Santiago, G., Alvarez, M. M., Tamayol, A., Annabi, N., and Khademhosseini, A. (2015). "Synthesis, properties, and biomedical applications of gelatin methacryloyl (GelMA) hydrogels," Biomaterials 73, 254-271. DOI: 10.1016/j.biomaterials.2015.08.045

Zhao, Y., Yao, R., Ouyang, L., Ding, H., Zhang, T., Zhang, K., Cheng, S., and Sun, W. (2014). "Three-dimensional printing of Hela cells for cervical tumor model in vitro," Biofabrication 6(3), Article ID 035001. DOI: 10.1088/1758-5082/6/3/035001

Article submitted: May 20, 2020; Peer review completed: July 12, 2020; Revised version received and accepted: Aug. 1, 2020; Published: August 5, 2020.

DOI: 10.15376/biores. 15.4.7357-7373 